\title{
Long term progression of joint damage in rheumatoid arthritis
}

\author{
D L SCOTT, B L COULTON, AND A J POPERT \\ From St Bartholomew's Hospital, West Smithfield, London; and the Droitwich Centre for Rheumatic \\ Diseases, Droitwich, Worcestershire
}

SUMMARY Joint damage in rheumatoid arthritis is assessed radiologically. Previous studies have not examined in detail its long term progression. We evaluated the overall changes of peripheral joint damage radiologically in 50 rheumatoid patients followed up at one rheumatology centre for 10 years. All peripheral joints were scored in 12 groups with Larsen's standard films at 0 and 10 years. In 48 cases the total scored deteriorated (mean increase $13 \%$ maximum damage). There was no different pattern of progression in any of the patients, though seropositive patients had more initial damage and a greater rate of progress. The wrist and small joints of the feet were most affected initially. During the 10 years most progression occurred in the wrist, knee, and metacarpophalangeal joints. Progression occurred in both initially normal and abnormal joints. By 10 years only $16.5 \%$ joint groups showed no damage. Complete destruction was most common in the wrist, knee, and small joints of the feet. Damage to the hands and wrists gave a good indication of overall changes at 0 and 10 years and also the increase in damage (correlation coefficients were from $r=0 \cdot 74$ to $r=0 \cdot 85$ ). These results show that specific joints are involved in different stages of the disease. Some joints are frequently involved and some less often. The hands and the wrists give a reasonable picture of the overall progression of damage.

Key words: radiological assessments.

Plain radiographs of peripheral joints serve three main purposes in rheumatoid arthritis (RA). The first is diagnosis and disease classification. The second is to define specific anatomical problems, such as whether the degree of joint damage is sufficient to merit surgery. The third role is determining disease progression. These applications utilise different types of information. Diagnostic applications concentrate on the specificity of radiological changes, and the earliest changes are important. Conversely, when using radiographs to determine the progression of joint damage it is more relevant to evaluate the overall pattern of change and to determine which joints give the most representative information concerning general progression.

There is considerable information on the earliest radiological changes of RA. ${ }^{12}$ Similarly, the relationship between the progression of changes seen in hand radiographs, and the clinical and laboratory

Accepted for publication 30 September 1985.

Correspondence to Dr D L Scott, Department of Rheumatology, St Bartholomew`s Hospital. West Smithfield. London EC1A 7BE. variables used to assess RA have also been studied in detail. ${ }^{3-9}$ There is, however, relatively little information about the overall progression of radiological evidence of joint damage in RA. Nor has it been clearly shown which joints provide a good index of progressive damage and which are especially involved in the destructive process. We have therefore studied in detail the progression of overall damage in RA. We have used the standard radiographs provided by Larsen $e$ al $^{10}$ as a basis for scoring the amount of radiological damage.

\section{Patients and methods}

PATIENTS

Fifty patients with classical or definite RA were studied. These patients had had persistent arthritis for at least one year before the study period and had been attending the Droitwich Centre for Rheumatic Diseases for at least 10 years of follow up. Between these two time points all patients attending clinic had had a complete initial and 10 year (final) set of 
radiographs of the peripheral joints. The patients included in the study were consecutive cases attending the outpatient clinic who had been seen for this period of time. There were 36 females and 14 males. Repeated Rose-Waaler tests for the presence of rheumatoid factor showed that 34 patients were seropositive and 16 were persistently seronegative. The mean initial duration of disease was 7.5 years (SD 6.8), with a range of one to 24 years. All patients were followed up for as near to 10 years as possible; the mean duration of follow up was 9.7 years (SD 1.4). During the study period patients were treated with non-steroidal anti-inflammatory drugs, analgesics, slow acting antirheumatic drugs, and corticosteroids, often in combination. The way in which these patients have been treated has been previously described in another long term study from Droitwich. ${ }^{11}$

\section{$x$ RAY A S S S S MEN TS}

The patients had initial and final plain radiographs showing the following joints: distal interphalangeal (DIP), proximal interphalangeal (PIP), metacarpophalangeal (MCP), wrist, elbow, shoulder, hip, knee, ankle, tarsus, hallux first interphalangeal (IP), and metatarsophalangeal (MTP). Each of these groups of joints was scored with Larsen's standard films on a $0-5$ point scale. ${ }^{10}$ The average score for each pair of joints or group of joints was recorded. DIP, PIP, MCP, and MTP joints were analysed as groups; the other joints were considered singly. The scores were expressed separately for each joint as the percentage of maximum possible damage. The scores for all the joints were then added and expressed, again as the percentage of maximum total possible damage. The reproducibility of our scoring system has previously been investigated. ${ }^{12}{ }^{1.3}$ For this study all the radiographs were read by a single observer (BLC), without knowledge of the order in which the films had been taken, or of the scores in the other joints of an individual patient.

\section{Results}

CHANGES IN TOTAL JOINT SCORE

In 48 of the 50 patients the total score increased. The mean change was an increase of $13 \%$ in the maximum total possible damage from an initial mean of $22 \%$ to $35 \%$ at 10 years. The most marked increase in individual total score was $48 \%$ (from 7 to $55 \%$ ). The results are shown in Fig. 1. There was no identifiably different pattern of progression of joint damage in any group of patients defined in terms of age, sex, seropositivity, or disease duration. The 34 seropositive patients had more initial joint damage, and had significantly greater joint damage at the end of the study period than the 16 seronegative patients (Table 1).

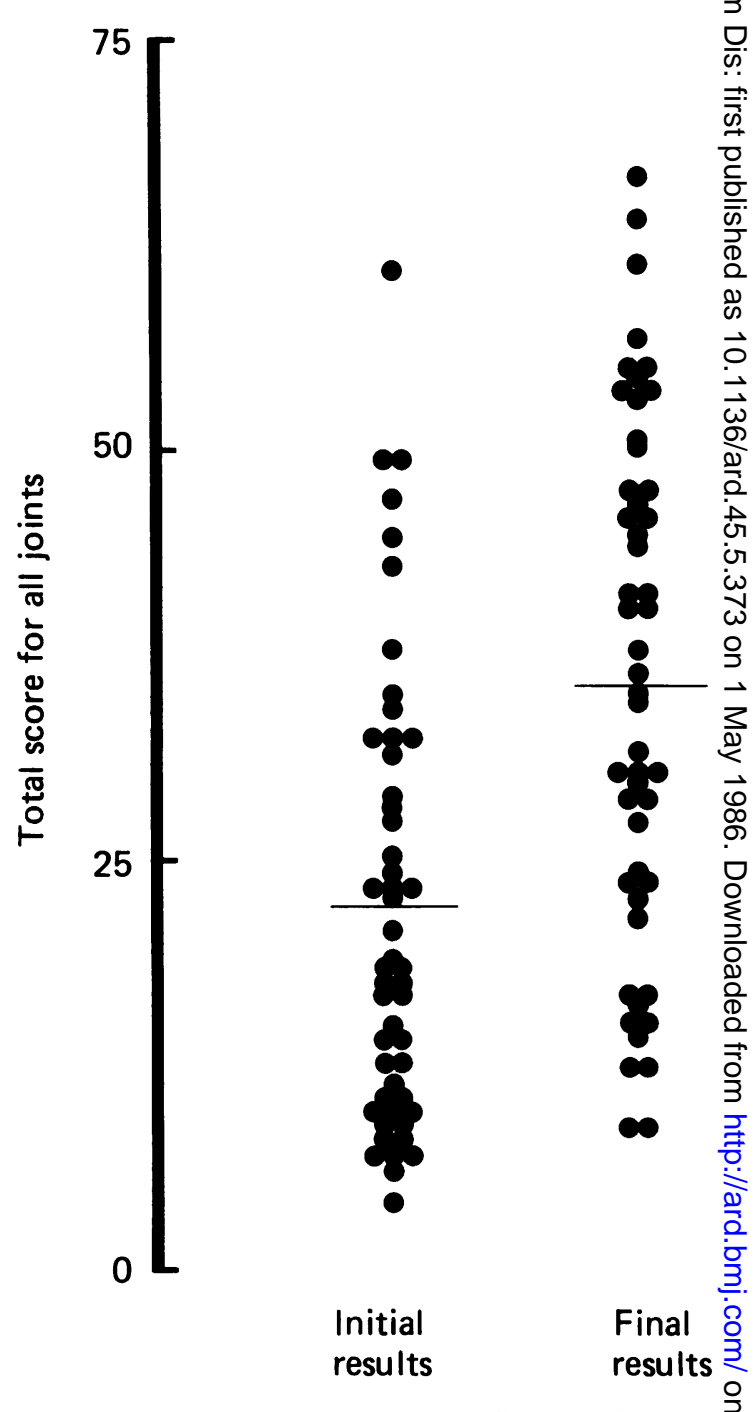

Fig. 1 Initial and final total scores for all joints. The group means are indicated. Scores are expressed as percentage maximum total possible damage.

Table 1 Effects of rheumatoid factor status on radiologicalర findings. Radiological scores are expressed as percentage maximum total possible damage

\begin{tabular}{lllll}
\hline $\begin{array}{l}\text { Rheumatoid } \\
\text { factor status }\end{array}$ & No & $\begin{array}{l}\text { Mean initial } \\
\text { scores (SD) }\end{array}$ & $\begin{array}{l}\text { Mean final } \\
\text { scores (SD) }\end{array}$ \\
\hline Positive & 34 & $24(14)$ & $39(15)^{*}$ & $27(15)$ \\
Negative & 16 & $19(12)$ & (19)
\end{tabular}

*Significantly more than seronegative cases by Student's unpaired $t$ test $(\mathrm{p}<0 \cdot 02)$. 
PROGRESSION OF DAMAGE IN VARIOUS JOIN T GROUPS

Initially the wrists and the small joints of the feet showed most damage (Table 2). During the study period most progression occurred in the wrists, the knees, and the MCP joints, and there was less

Table 2 Distribution of radiological changes among different joint groups showing mean results for initial and final scores and also mean increases in scores.

The scores are expressed as percentage maximum possible damage

\begin{tabular}{llll}
\hline Joints & $\begin{array}{l}\text { Mean } \\
\text { initial } \\
\text { scores }\end{array}$ & $\begin{array}{l}\text { Mean } \\
\text { final } \\
\text { scores }\end{array}$ & $\begin{array}{l}\text { Mean } \\
\text { increases } \\
\text { during } \\
10 \text { years }\end{array}$ \\
\hline Distal interphalangeal & 17 & 26 & 9 \\
Proximal interphalangeal & 25 & 36 & 11 \\
Metacarpophalangeal & 20 & 36 & 16 \\
Wrist & 38 & 61 & 23 \\
Elbow & 15 & 30 & 15 \\
Shoulder & 12 & 27 & 15 \\
Hip & 8 & 18 & 10 \\
Knce & 20 & 41 & 21 \\
Ankle & 7 & 17 & 10 \\
Tarsus & 22 & 33 & 11 \\
Metacarpophalangeal & 36 & 51 & 15 \\
First interphalangeal & & & \\
$\quad$ (hallux) & 31 & 37 & 6 \\
\hline
\end{tabular}

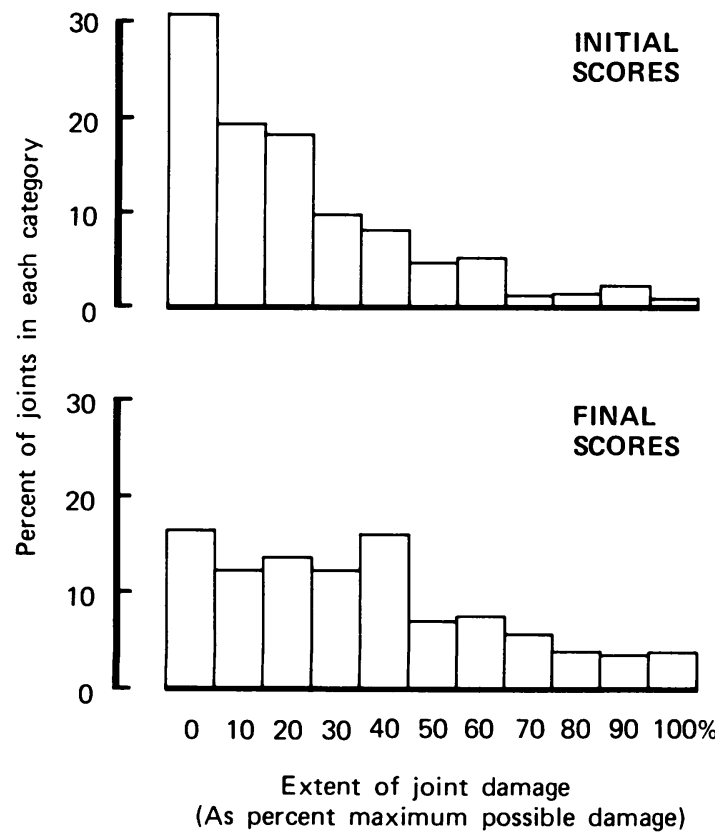

Fig. 2 The initial and final scores for individual joints expressed as the percentage of joints in each category of joint damage. The categories are defined as ten percentiles of maximum possible damage. progression in the small joints of the feet. The knees showed most progressive damage, and this was striking in comparison with changes in the hips and ankles.

DISTRIBUTION OF JOINT DAMAGE

The initial and final scores for individual joints were analysed in terms of the number of joints in each tenth percentile of maximum possible damage. These percentiles were considered as separate categories of damage (Fig. 2). In over $30 \%$ of joints initial radiographs showed no damage, and this had fallen to only $16.5 \%$ of joints by the final analysis. All joints showed a general tendency to increasing damage during the study period. Radiologically normal joints and those with considerable damage were equally likely to progress.

Joints which had the highest scores at 10 years and fell into the categories of $80 \%$ or more maximum damage were analysed in detail. There were 28 patients who had final scores for one or more joints within these categories. This involved 56 different joint groups. In nine patients only one joint group was in this category. There were 15 patients who had two or three joint groups in this category, and in four patients there were four joint groups. Analysis of the initial scores of these greatly damaged joints

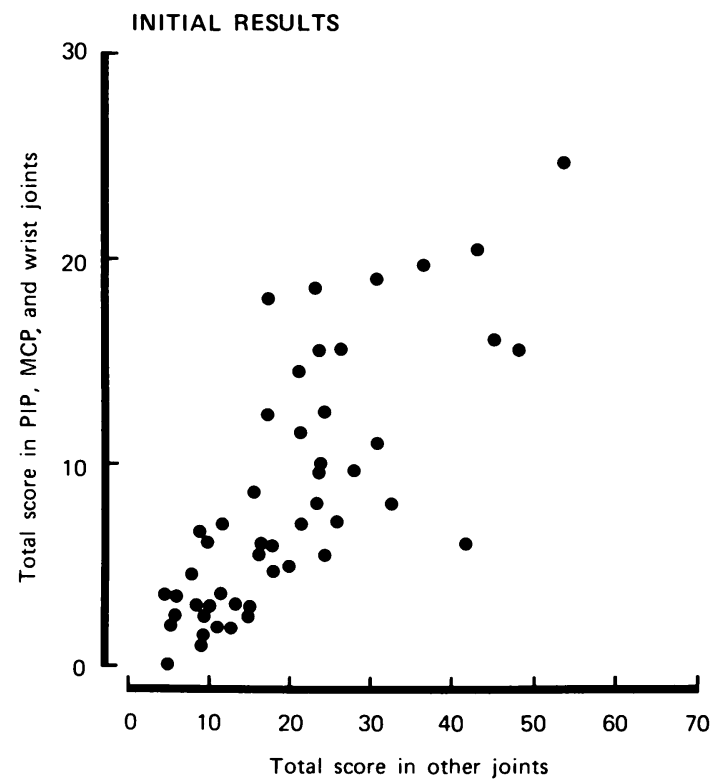

Fig. 3 The relationship between the initial scores in the PIP, MCP. and wrist joints and the scores in all other joints. There was a highly significant correlation $(r=0 \cdot 85$; $p<0 \cdot(0) 1)$. Scores are expressed as percentage maximum possible damage. 
showed that in six cases the joints were radiologically normal when first scored. In a further six cases they had less than $20 \%$ total damage during the initial assessment, and in only 20 cases were the joints already severely involved (i.e., $80 \%$ or more maximum damage). This high degree of damage was most commonly found in the wrist joints, and 19 of the 56 severely damaged joints were wrists. The other joints to be particularly affected were the knee and the MTP joints. The majority of other joints were involved occasionally. However the DIP, PIP, and tarsus were never so severely involved.

PREDICTIVE VALUE OF RADIOLOGICAL CHANGES IN THE HANDS AND WRISTS We analysed the relationship between changes in the hands and wrists alone (i.e., PIP, MCP, and wrist joints) and those changes seen in other joints. We made three analyses comparing the initial scores, the final scores, and the increase in scores during the study period. There were significant correlations in each case $(r=0.85,0.79,0.74$ respectively; $p<0.001$ in all cases. This is illustrated in Figs 3 and 4 . Thus examination of the hands and

FINAL RESULTS

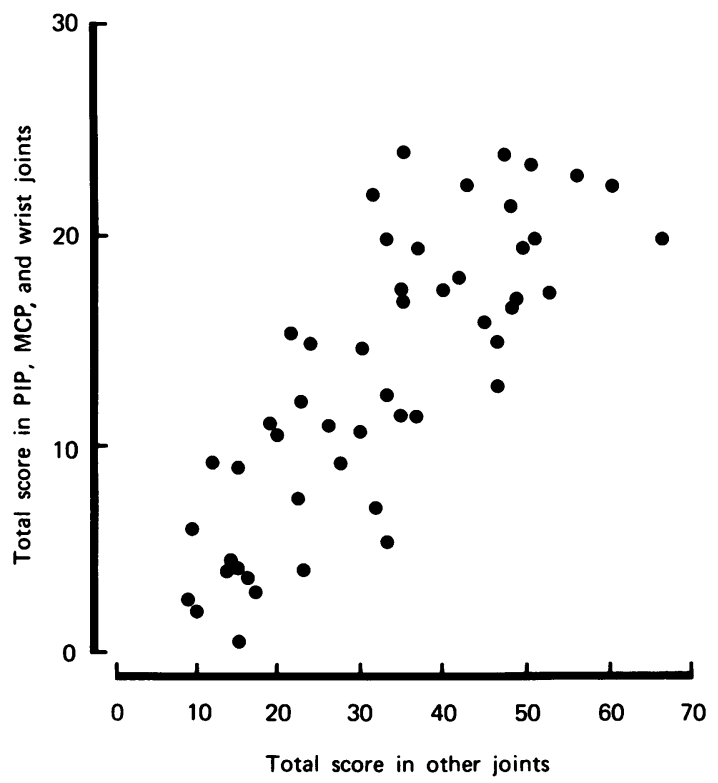

Fig. 4 The relationship between the final scores in the $P I P, M C P$, and wrist joints and the scores in all other joints. There was a highly significant correlation $(r=0 \cdot 79$; $p<0 \cdot 001$ ). Scores are expressed as percentage maximum possible damage.

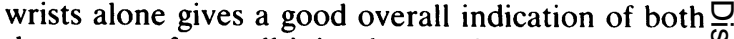
the extent of overall joint damage in any given time and the rate of progression of damage. However, $\stackrel{\vec{m}}{\stackrel{5}{*}}$ further analysis of the results also indicated it waso impossible to predict from the radiographs of the $\frac{C}{0}$ hands and wrists whether there would be significant $\overline{\bar{c}}$ damage involving the large joints in an individual $\mathbb{Q}$ patient. The hands and wrists were predictive only of the composite score of other small and large joints.

\section{Discussion}

The progression of joint damage in RA is a complex process producing a diverse pattern of involvement $\mathrm{G}$ in different joint groups. Our results show that some $i r$ joints are involved early in the course of the disease, $\omega$ while others are involved later. The MTP and hallux $\omega$ interphalangeal joints are the best examples of early $\mathrm{O}$ involvement; Brook et al have previously described $\rightarrow$ the early involvement of these joints, ${ }^{2}$ and our own results confirm their observations. These joints, however, do not show so much later damage. Nor $\vec{\otimes}$ are all the joints in the feet equally likely to show damage; for example, the ankles are infrequently involved, as we have recently reported. ${ }^{13}$ The knees are a good example of later joint involvement and were frequently damaged during the study period. There are several possible reasons for the differen- $\mathbb{D}$ tial time course of damage to different joint groups. The first possibility is that the technical constraints of joint radiology mean that different appearances will be given by damage to the small peripheral joints in the hands and feet compared with large joints such as the knees. There is some evidence to support this; damage to the knees is often more $\frac{0}{0}$ severe than shown radiologically. ${ }^{14}$ It is also undeni- 3 . able that comparisons of large and small joints are $\delta$ evaluating different types of structure and must $₹$ therefore be open to some difficulties in interpret- $\mathrm{O}$ ation. At the same time other pathological aspects could be important. Mechanical factors could have a을 significant role in the development of radiological $\stackrel{\bar{N}}{-}$ damage; The asymmetric distribution of joint dam- $\sigma$ age in RA patients in relation to the dominant hand $N$ supports this possibility: the severity of damage is more marked on the dominant side. ${ }^{15}$ Thus the small 0 joints of the feet might be damaged early as a result ${ }_{0}$ of the mechanical factors acting upon them. Equally $\frac{D}{\Phi}$ the involvement of the knee joints could follow from $\stackrel{?}{+}$ an alteration in the forces acting on them after 0 ligamentous damage and other changes induced by prolonged rheumatoid synovitis. Another relevant $\stackrel{\varnothing}{\Omega}$ consideration is the induction of secondary osteoar- $\frac{\overrightarrow{\mathbb{D}}}{\mathbb{Q}}$ thritic joint damage in the later stage of RA. The $\frac{\square}{0}$ Larsen score may well be influenced by the develop- 
ment of osteoarthritic change superimposed upon RA.

There have been relatively few studies of overall joint damage in RA. Larsen, ${ }^{10} 1617$ DeCarvalho et al, ${ }^{18}{ }^{19}$ and Luukkainen $e t a l,{ }^{20}{ }^{21}$ have all investigated this complex subject using the Larsen standard films. Our own results enlarge upon their findings. Our most clinically important result is that radiological changes in the hands and wrists show a reasonably good correlation with the damage in other joints. That does not mean that in a given individual one can predict damage to large joints from the findings in the hands and wrists. The degrees of correlation we have found, however, upholds the use of hand and wrist radiographs as the basis for estimating progressive joint damage in patients receiving antirheumatic therapy. We conclude that radiographs of the hands and wrists give representative information about general progression. This relationship has not been previously evaluated in detail.

The frequency and severity of wrist joint involvement is a striking feature of our findings, which may result from its anatomical situation as we have discussed for other joints. Larsen has recently described the use of a more detailed analysis of wrist joints to produce a radiological score ${ }^{22}$ and this could give a somewhat different view of wrist joint changes, though there is no evidence to support such an assertion. The relative contribution between erosive damage and loss of joint space has been the subject of considerable debate, and Gofton has implied that the changes in the wrists due to loss of joint space are greater than those due to erosive damage. ${ }^{23}$ This is also supported by the results from the carpal/metacarpal ratios described by Trentham and Masi. ${ }^{24}$ The standard films provided by Larsen make it difficult to differentiate between the two degrees of changes in the wrists at the destructive end of the scale. It is quite possible that loss of joint space is a predominant change in the wrist when using the Larsen films, which reinforces the view that there are differing pathological mechanisms causing damage to different joint groups. There are no joints which are entirely spared, though some such as the ankle are infrequently involved. The traditional view that DIP joints are normally spared in RA is not substantiated by our findings, though Campion et al in a small cross sectional study have already shown the relative frequency of DIP joint involvement. ${ }^{25}$

The attractive concept that initially normal joints will not be damaged by RA if treatment is instituted is not completely supported by our findings. Approximately half of the initially normal joints were damaged by the end of the study, and there was a gradual increase in the number of severely involved joints. It would be premature to dismiss the view that effective therapy limits progression of joint damage as there is a considerable body of supporting evidence. ${ }^{26-32}$ It is quite possible that some of our patients had a poor response to treatment and these were the ones that showed progressions. Further work on individual responses is needed to examine in detail this important question.

The predictive factors to joint damage have been the centre of considerable recent interest. ${ }^{4-733}$ In general, neither the type of onset nor clinical and laboratory findings give a clear indication of the extent of disease progression. Our own findings that there is a moderate increase in joint damage in seropositive patients support these previous results, while underlining the weak nature of the association between rheumatoid factor positivity and radiological evidence of joint damage. It also supports the conclusions of Griffin et al, who showed a similar relationship between seropositivity and progression. ${ }^{34}$ We have, however, been unable to substantiate the suggestion of Burns and Calin that there is a different distribution of joint damage in seropositive and seronegative patients. ${ }^{35}$ Possible explanations for their different conclusions are a variation in patient selection and a different definition of seropositivity. We feel it inappropriate to suggest a different pathological mechanism may be involved in seronegative and seropositive disease.

\section{References}

1 Jacoby R K, Jayson M I V, Cosh J A. Onset, early stages, and prognosis of rheumatoid arthritis: a clinical study of 100 patients with 11-year follow-up. Br Med J 1973; ii: 96-100.

2 Brook A, Fleming A, Corbett M. Relationship of radiological changes to clinical outcome in rheumatoid arthritis. Ann Rheum Dis 1977; 36: 274-5.

3 Young A, Corbett M, Brook A. The clinical assessment of joint inflammatory activity in rheumatoid arthritis related to radiological progression. Rheumatol Rehabil 1980; 19: 14-9.

4 Scott D L, Grindulis K A, Struthers G R, Coulton B L, Popert A J, Bacon P A. The progression of radiological changes in rheumatoid arthritis. Ann Rheum Dis 1984; 43: 8-17.

5 Scott D L, Dawes P T, Fowler P D, Grindulis K A, Shadforth $M$, Bacon $P$ A. Anti-rheumatic drugs and joint damage in rheumatoid arthritis. $Q J$ Med 1985; 54: 49-59.

6 Luukkainen R, Kaarela K, Isomäki H, et al. The prediction of radiological destruction during the early stages of rheumatoid arthritis. Clin Exp Rheumatol 1983; 1: 295-8.

7 Ingeman-Nielwn $M$, Halskov $O$, Hamsen $T M$, Halberg $P$, Stage $P$, Lorenzen I. Clinical synovitis and radiological lesions in rheumatoid arthritis. Scand $J$ Rheumatol 1983; 12: 237-40.

8 De Carvalho A, Graudal H. Radiographic progression of rheumatoid arthritis related to some clinical and laboratory parameters. Acta Radiol [Diagn] (Stockh) 1980; 21: 551-5.

9 Amos R S, Constable T J, Crockson R A, Crockson A P, McConkey B. Rheumatoid arthritis: relation of serum Creactive protein and erythrocyte sedimentation rates to radiographic changes. $\mathrm{Br}$ Med J 1977; i: 195-7. 
10 Larsen A. Dale K. Eck M. Radiographic evaluation of rheumatoid arthritis and related conditions by standard reference films. Acta Radiol (Diagn/ (Stockh) 1977; 18: 481-91.

11 Scott D L, Coulton B L, Chapman J H, Bacon P A, Popert A J. The long-term effects of treating rheumatoid arthritis. $J R$ Coll Physicians Lond 1983; 17: 79-85.

12 Grindulis K A. Scott D L, Struthers G R. The assessment of radiological changes in the hands and wrists in rheumatoid arthritis. Rheumatol Int 1983; 3: 39-42.

13 Scott D L, Coulton B L, Bacon P A. Popert A J. Methods of $\mathrm{X}$-ray assessment in rheumatoid arthritis: a re-evaluation $\mathrm{Br} J$ Rheumatol 1985; 24: 31-9.

14 Duncan H, Riddle J, Brennan T, Ellis B, Pitchford W. Standard knee radiographs are a poor index of trabecular bone damage. Arthritis Rheum 1984; 27 (suppl): 552.

15 Owsianik W D J, Kundi A. Whitehead N, Kraag G R, Goldsmith C. Radiological articular involvement in the dominant hand in rheumatoid arthritis. Ann Rheum Dis 1980; 39: 508-10.

16 Larsen A. Radiological grading of rheumatoid arthritis, an interobserver study. Scand J Rheumatol 1973; 2: 136-41.

17 Larsen A, Edgren J, Harju E, Laasonen L, Reitamo T. Interobserver variation in the radiological changes of rheumatoid arthritis. Scand J Rheumatol 1979; 8: 109-12.

18 De Carvalho A, Graudal H, Jordensen B. Radiologic evaluation of the progression of rheumatoid arthritis. Acta Radiol [Diagn] (Stockh) 1980; 21: 115-21.

19 De Carvalho A. Discriminative power of Larsen's grading system for assessing the course of rheumatoid arthritis. Rheumatol Int 1983: 22: 77-80.

20 Luukkainen R, Kajander A. Isomäki H. Effect of gold on progress of erosions in rheumatoid arthritis. Scand J Rheumatol 1977; 6: 189-92.

21 Luukkainen R, Isomäki H, Kajander A. Effect of gold treatment on the progression of crosions in RA patients. Scand J Rheumatol 1977; 6: 123-7.

22 Larsen A. Horton K. Osborne C. Auranofin compared with intramuscular gold in the long-term treatment of rheumatoid arthritis: and X-ray analysis. In: Capell H A, Colc D S, Manghani K K, Morris R W, eds. Auranofin Amsterdam: Excerpta Medica, 1983; 264-77.
23 Gofton J P. Problems associated with the measurement of radiologic progression of disease in rheumatoid arthritis. $J$ Rheumatol 1983; 10: 177-9.

24 Trentham D E. Masi A T. Carpo metacarpal ratio. A new quantitative measure of radiologic progression of wrist involvement in rheumatoid arthritis. Arthritis Rheum 1976: 19: 939-44.

25 Campion G, Dieppe P, Watt I. Herberden's nodes in osteoarthritis and rheumatoid arthritis. $\mathrm{Br}$ Med $J$ 1983; 287: 1512 .

26 Wright V, Amos R. Do drugs change the course of rheumatoid arthritis? $\mathrm{Br}$ Med J 1980: 280: 193-4.

27 Iannauzzi L, Dawson N. Zein N, Kushner I. Does any therapy slow radiographic deterioration in rheumatoid arthritis? $N$ Engl J Med 1983; 309: 1023-7.

28 Co-operating Clinics Committee of the American Rheumatism Association. A controlled trial of gold salt therapy in rheumatoid arthritis. Arthritis Rheum 1973; 16: 353-8

29 Sigler J W, Bluhm G B, Duncan H, Sharp J T, Ensign D C. McCrann W R. Gold salts in the treatment of rheumatoid arthritis. A double blind study. Ann Intern Med 1974: 80: 21-6.

30 Co-operating Clinics Committec of the American Rheumatism Association. A controlled trial of cyclophosphamide in rheumatoid arthritis. $N$ Engl J Med 1970; 283: 883-9.

31 Joint Committee of the Medical Research Council and the Nuffield Foundation. A comparison of prednisolone with aspirin or other analgesics in the treatment of rheumatoid arthritis. Ann Rheum Dis 1959; 18: 173-86.

32 Joint Committee of the Medical Research Council and the Nuffield Foundation. A comparison of prednisolone with aspirin or other analgesics in the treatment of rheumatoid arthritis. Ann Rheum Dis 1960: 19: 331-7.

33 Luukkainen R, Isomäki H, Kajander A. Prognostic value of the type of onset of rheumatoid arthritis. Ann Rheum Dis 1983; 42: 274-5.

34 Griffin J, Celinska E, Panayi G S, Gibson T. Grahame R. A radiological study of seronegative and seropositive rheumatoid arthritis. Br J Rheumatol 1985: 24: 92.

35 Burns $T$ M, Calin $A$. The hand radiograph as a diagnostic discriminant between seropositive and seronegative 'rheumatoid arthritis': a controlled study. Ann Rheum Dis 1983; 42: $605-12$. 